"This is the peer reviewed version of the following article: [Drug and Alcohol Review, 2019, 38 (5), pp. 465 - 472], which has been published in final form at [https://doi.org/10.1111/dar.12958] This article may be used for non-commercial purposes in accordance with Wiley Terms and Conditions for Self-Archiving 


\title{
Harmless? A hierarchical analysis of poppers use correlates among young gay and bisexual men
}

\author{
Daniel Demant, $\mathrm{PhD}^{\mathrm{a}, \mathrm{b}^{*}}$ \& Oscar Oviedo-Trespalacios, $\mathrm{PhD}^{\mathrm{c}}$
}

${ }^{a}$ Lecturer, Australian Centre for Public and Population Health Research, Faculty of Health, University of Technology Sydney, Ultimo, Australia

${ }^{b}$ Visiting Fellow, School of Public Health and Social Work, Faculty of Health, Queensland University of Technology (QUT), Brisbane, Australia

${ }^{c}$ Research Fellow, Centre for Accident Research and Road Safety-Queensland (CARRS-Q), Institute of Health and Biomedical Innovation (IHBI), Faculty of Health, Queensland University of Technology (QUT), Brisbane, Australia

\section{*Corresponding Author}

Dr Daniel Demant

Lecturer in Public Health

Australian Centre for Public and Population Health Research

Faculty of Health

University of Technology Sydney

235-253 Jones Street, Ultimo, New South Wales 2007, Australia

Tel: +610295145499

Email: daniel.demant@uts.edu.au

\section{ORCiD}

Daniel Demant: 0000-0003-3330-2972

Oscar Oviedo-Trespalacios: 0000-0001-5916-3996 


\title{
Running title: Poppers use among young gay and bisexual men
}

\begin{abstract}
Introduction: Poppers (alkyl nitrites) are recreational substances commonly used during sexual activity. The current legal status of poppers is complex and wide-ranging bans are increasingly under discussion. Research has identified disproportionate levels of poppers use in sexual minority men. While research on poppers use among sexual minority men exists, little is known about poppers use patterns and correlations with psycho-social and other factors among gay and bisexual young men.

Methods: A cross-sectional survey was conducted with 836 Australian gay and bisexual young men aged 18 to 35 years. Descriptive statistics and hierarchical segmentation analyses were conducted to identify poppers use patterns, and correlates of recent poppers use (past three months) with personal characteristics, use of other substances, as well as mental and psycho-social health including minority stress, LGBT-community connectedness and participation.

Results/Conclusion: High levels of lifetime $(38 \%, n=315)$ and recent $(24 \%, n=204)$ poppers use were reported. However, few participants reported dependency symptoms, risky consumption or problems arising from using poppers. The final model included three variables (visiting sex-on-premises venues, licensed LGBT venues, and using other substances) and predicted $85 \%(\mathrm{n}=174)$ of recent poppers use. No correlations with other concepts or characteristics could be identified. This analysis further supports the hypothesis that poppers may be substances with a comparably low risk profile. A regulation of poppers with a harm reduction approach may present a valuable public health intervention.
\end{abstract}

Keywords: Substance Use, Alkyl Nitrites, Men Who Have Sex With Men, Minority Health 


\section{Introduction}

'Poppers' is a common term used to refer to recreational substances with an active ingredient from the alkyl nitrite class (1), most commonly amyl nitrite $\left(\mathrm{C}_{5} \mathrm{H}_{11} \mathrm{ONO}\right)$ but also butyl $\left(\mathrm{C}_{4} \mathrm{H}_{9} \mathrm{NO}_{2}\right)$, isobutyl $\left(\mathrm{C}_{4} \mathrm{H}_{9} \mathrm{NO}\right)$, isopropyl $\left(\mathrm{C}_{3} \mathrm{H}_{7} \mathrm{NO}_{2}\right)$ or pentyl nitrite $\left(\mathrm{C}_{5} \mathrm{H}_{11} \mathrm{NO}_{2}\right)$. These substances are clear liquids with a strong scent that are inhaled through the nostrils (2). Effects set in within a few seconds and last for a few minutes depending on dosage and user (3).

Poppers were originally intended to aid in the treatment of heart conditions, particularly angina, but became increasingly popular due to other effects. Depending on expectancies of poppers use in individuals and the context in which these are used, effects may include mild euphoria and a heightened state of sexual arousal (4), as well as relaxant effects on certain muscles including the sphincter and vagina (5). Poppers are most commonly used before or during sexual activity (6) but have always been used outside of sexual contexts, and an increase in non-sexual recreational use among young people has been registered in different jurisdictions (7). While poppers are used by populations of all sexual identities, research has shown that gay and bisexual men are disproportionately more likely to use these. A recent international survey (8) reported that, in comparison to heterosexual men, those identifying as gay or bisexual had adjusted odds ratios of lifetime poppers use of 5.1 and 1.88, respectively. Last month use was also significantly higher with $1.5 \%$ among heterosexual men compared to $16.2 \%$ and $4.5 \%$ among gay and bisexual men, respectively. Similarly, two Australian studies reported high levels of recent use with up to $38 \%$ of sexual minority men reporting poppers use in the past six months $(9,10)$. Older sexual minority men also appear to be more likely to use poppers than their younger counterparts with a recent study from Australia reporting that $23 \%$ of participants aged 16 to 24 years of age used poppers in the past 6 months compared to $41 \%$ among those aged 30 to 39 years (11). Overall, these results are consistent with a European study showing that poppers products are the third most commonly used substance among gay and bisexual men, after alcohol and tobacco (12).

Poppers do not cause physical dependencies; however, studies suggest that some users may develop psychological dependencies and depend on the use of the substance to engage in satisfactory sexual activity (13-15). Side effects of poppers use are overall described as small, particularly in comparison to other substances, but may include skin lesions (around the nostrils and lips), reflex tachycardia, vasodilation, brief hypotension, dizziness, flushing, and methaemoglobinemia (16). Poppers may lead to severe hypotension, myocardial infarction and death when combined with phosphodiesteraseinhibiting medications (e.g., sildenafil) used to treat erectile dysfunction and pulmonary arterial hypertension $(16,17)$.

Past research reported correlations between poppers use and sexual risk behaviours as well as undiagnosed HIV infections and a heightened risk of seroconversion in men who have sex with men $(10,18,19)$. Research on psychosocial consequences, LGBT community identification and mental 
wellbeing of poppers use among gay and bisexual men is scarce. However, a recent study from Australia reported that men who have sex with men who use poppers were less likely to show symptoms of depression, more likely to be engaged with other gay men, and more likely to consider themselves to be masculine (20).

Poppers have historically been described as a part of the wider gay culture $(21,22)$. A 2018 interim decision by the Therapeutic Goods Administration (2) to amend Australia's Poisons Standard by rescheduling poppers from Schedule 4 (Prescription Only) to Schedule 9 (Prohibited Substance) was met with strong resistance from the community, calling the decision an attack or war on gay and bisexual men and their community $(23,24)$. Partial or complete bans in other jurisdictions have attracted similar criticism in the past (25). The legal status of poppers is generally complex and contentious (2). While marketing poppers as a recreational substance is illegal in Australia, it is commonly sold in adult and online shops as 'room deodoriser', 'leather cleaner' or 'VHS head cleaner', falsely assuming that such labels will bypass existing regulations (2). Some jurisdictions have banned certain alkyl nitrites for any non-commercial use, such as isobutyl nitrite in the European Union due to evidence suggesting a higher prevalence of retinal damage compared to other alkyl nitrites (26) or amyl nitrite in the United States (27).

As discussed above, many studies on the impact of poppers on sexual (risk) behaviour and physiological side effects have been published. However, research focusing on relationships between poppers use and psycho-social factors as well as other concepts such as LGBT community connectedness and participation in gay and bisexual men is limited, particularly among young sexual minority men. Previous research identified strong correlations between the use of substances and concepts such as participation in and connectedness to the LGBT community in sexual minority men from which implications for public health practice, including health promotion, and further research into substance use in this population were drawn (28-30). The aim of this study is, therefore, to identify patterns of poppers use in young gay and bisexual men, and to explore correlates of poppers use with participation in and connectedness to the LGBT community, mental and psychosocial wellbeing, as well as other substance use and personal characteristics. 


\section{Materials and Methods}

\section{Recruitment and participants}

A cross-sectional survey on substance use was completed by 836 sexual minority men between November 2016 and April 2017. Recruitment was conducted using paid and unpaid advertisement on social media platforms including Facebook ${ }^{\circledR}$ as well as through LGBT community organisations, LGBTIQ media, and commercial LGBTIQ-venues. Potential participants had to reside in Australia and were aged between 18 and 35 years to ensure sufficient commonalities. Research ethics approval was obtained from Queensland University of Technology's Human Research Ethics Committee (approval number: 1600000636). Informed consent was sought from all participants.

\section{Measurements}

\section{Demographics}

Demographic information on age, gender, sexual minority identity, country of birth, ethnicity, living area, and education status were collected. Sexual minority and gender identity categories were developed after community consultations and participants were offered an extensive list. However, only participants identifying as men (self-identification including participants identifying as cisgender men and transgender men) were included for the purpose of this analysis.

\section{Poppers use behaviour}

Participants were asked about their use of poppers in their lifetime, past year, past three months and past month. Participants who have indicated any use of poppers in their lifetime were also asked to complete a poppers-specific version of the valid and reliable (31) WHO Alcohol, Smoking and Substance Involvement Screening Test (ASSIST) to calculate a specific substance involvement score (Range: 0-39). A score between 0 and 3 indicates low risk use, scores between 4 and 26 indicate moderate risk and scores of 27 or above indicate high risk use patterns. Scores are calculated from seven items:

(1) In your life, have ever used poppers/amyl/alkyl nitrites? (Yes/No)

(2) In the past three months, how often have you used poppers/amyl/alkyl nitrites? (Never, Once or Twice, Monthly, Weekly, Daily or Almost Daily)

(3) During the past three months how often have had a strong desire or urge to use poppers/amyl/alkyl nitrites? (Never, Once or Twice, Monthly, Weekly, Daily/Almost Daily) 
(4) During the past three months how often has your use of poppers/amyl/alkyl nitrites led to health, social, legal or financial problems? (Never, Once or Twice, Monthly, Weekly, Daily/Almost Daily)

(5) During the past three months, how often have you failed to do what was normally expected of you because of your use of poppers/amyl/alkyl nitrites? (Never, Once or Twice, Monthly, Weekly, Daily/Almost Daily)

(6) Has a friend or relative or anyone else ever used poppers/amyl/alkyl nitrites? (No, never; Yes, in the past three months; Yes, but not in the past three months)

(7) Have you ever tried and failed to control, cut down or stop using poppers/amyl/alkyl nitrites? (No, never; Yes, in the past three months; Yes, but not in the past three months)

Data on these variables were also collected for other common substances: Alcohol, THC/Cannabis, Tobacco, MDMA/Ecstasy, Hallucinogens, Amphetamines, Cocaine, Inhalants (excluding Poppers), Methamphetamines, GHB/GBL, Opioids, Steroids (non-prescriptive), and misuse of prescription medicine.

\section{Other variables}

Other variables included in this analysis are: Connectedness to the LGBT Community Scale (32), Participation in the LGBT Community Scale (33, 34), Drug-Taking Confidence Questionnaire (35), Substance Use Motives Scale (36), Mental Health Continuum - Short Form for Adults (37), Kessler10 Psychological Distress Scale (38), Brief Resilience Scale (39), Minority Stress Scales (violence and harassment, and sexual orientation conflict) (40), Coping Inventory for Stressful Situations (41), Alcohol Use Disorder Identification Test C (42), and religious beliefs, values and practices.

\section{Statistical analysis}

\section{Construct reliability and validity}

Cronbach's alpha was used to analyse the internal consistency of constructs. Scales ranged between 0.87 and 0.93 with the exception of the Participation in the LGBT Community Scale (0.63). Further confirmatory factor analyses were conducted on adapted scales (Connectedness to the LGBT Community, and the sexual orientation conflict subscale of the Minority Stress Scale) demonstrating a good fit with normed fit indexes and comparative fit indexes values exceeding 0.95 (43). Exploratory and confirmatory factor analyses were performed for the newly developed Participation in the LGBT Community Scale. An exploratory factor analysis using a random half of the sample identified 5 items (Kaiser-Meyer-Olkin Measure of Sampling Adequacy $=0.789, p \leq 0.001$ ). The 
model demonstrated good fit in a confirmatory factor analysis with the remaining half of participants $(\mathrm{NFI}=0.96, \mathrm{CFI}=0.96)$.

\section{Poppers use correlations}

A hierarchical segmentation analysis (HAS) via decision trees was utilised to investigate correlations of recent poppers use with other variables (LGBT community specific variables (LGBT Community Participation and LGBT Community Connectedness), mental and psychosocial health and wellbeing, other substance use, and personal characteristics). The HAS via decision trees method is used to detect interactions between variables and belongs to a family of non-parametric methods using recursive partitioning to find patterns in large data sets $(44,45)$. The non-parametric nature of hierarchical segmentation analysis overcomes limitations which are usually related to linearity in model construction, allowing a wider diversity of applications. This is particularly advantageous for the analysis of the dataset utilised in this study, where normality and linearity are not always given. Decision trees are also robust to irrelevant or noisy variables, and outliers or errors. Public health research has identified machine learning approaches such as the decision tree method to be an alternative to more traditional analyses such as logistic regression (46).

From an algorithmic perspective, this automatic method seeks to split the variables into nodes, building the tree model through the growth of branches. The exhaustive CHAID (Chi-Squared Automatic Interaction Detection) data mining algorithm designed by Kass (47) was used in the present analysis. The exhaustive CHAID algorithm allows tree growth through sequential combination and division of population groups based on a statistical Chi-Square test. The starting node concentrates the whole population with each of the remaining subsequent nodes (children nodes) containing a portion of the population from the node located immediately above (parent nodes). In this particular case, the decision tree was used to assess the probability that participants reported recent poppers use, based on significant predictors from the variables described above. The decision tree was fitted using 10-fold cross-validation under the minimal-cost tree criterion, in other words, the tree with minimal cross-validation error has been selected. This technique has been used previously in substance use research (48) and other public health issues including risky driving behaviours (49), child labour (50) or occupational hygiene (51). Descriptive statistics have been used for poppers use and demographic variables. All analyses were conducted using AMOS 25 and SPSS 25 (IBM, New York, US). 


\section{Results}

\section{Demographics and general poppers use}

The final sample (see Table 1) for this analysis consisted of 836 gay and bisexual young men with a mean age of 23.4 years $(\mathrm{SD}=4.8)$. Most participants identified as gay $(81.6 \%, \mathrm{n}=682)$ and Caucasian/White $(82.3 \%, \mathrm{n}=688)$, lived in a major city $(69.3 \%, \mathrm{n}=579)$, and were born in Australia $(80.3 \%, \mathrm{n}=671)$.

[Insert Table 1 here]

Almost $40 \%$ of participants (see Table 1) have used poppers in their lifetime $(37.7 \%, \mathrm{n}=315)$ and a quarter of participants used poppers in the past 12 months $(24.4 \%, n=204)$. Recent poppers use was at $16.5 \%(\mathrm{n}=138)$ in the past three months, and $12.3 \%(\mathrm{n}=103)$ in the past month. The average age of onset of poppers use was 20.4 years $(\mathrm{SD}=3.6)$. Among those who ever used poppers (see Table 2), almost two-thirds $(64.8 \%, n=204)$ also used them in the past 12 months, with $43.8 \%(n=138)$ using poppers in the past three months and $32.7 \%(n=103)$ in the past month. Forty-two $(13.5 \%)$ participants used poppers at least once a week over the past three months and 27 (8.9\%) lifetime users showed a strong desire or urge to use poppers at least once a week. Few participants reported negative outcomes of their poppers use: $6.6 \%(n=20)$ of participants reported failing to control, cut down or stop their use in their lifetime, $5.2 \%(\mathrm{n}=16)$ reported that others have shown concern about their use of poppers at some point in their life. Nine (3.0\%) participants experienced health, social, legal or financial problems as a result of their use and $1.3 \%(n=4)$ of users reported that they failed to do what was normally expected of them as a result of poppers use. The WHO ASSIST poppers use sub-score was $3.1(\mathrm{SD}=4.4)$ among those who have ever used poppers.

[Insert Table 2 here]

\section{Correlation of recent poppers use}

The final CHAID tree consists of three layers (depths), 11 groups, and six terminal groups (see Figure 1). CHAID three predicted four significant correlations at $p \leq 0.05$. Two of these were LGBT Community participation variables ('visited an LGBT sex on premises venue in the last 12 months') and ('visited an LGBT pub/bar/café in the last 12 months'). The two other significant correlations were substance use variables (any illicit substance use in the past three months which does not 
include poppers use and past three months tobacco use). No mental and psychosocial health variables, demographic characteristics or other LGBT community-specific concepts were significant predictors of recent poppers use.

The final CHAID tree predicted $85.3 \%$ of all cases, with the goodness of model fit further confirmed by the chi-square test threshold maintained in all branches. The 'risk' of misclassifying a participant who consumed poppers in the last three months was estimated to approximately $15 \%$. Three predictive levels were identified:

[Insert Figure 1 here]

- Level 1: Visiting a sex-on-premises venue in the past 12 months

The proportion of participants who reported recent poppers use was larger among those who visited a sex-on-premises venue in the past 12 months. $11.1 \%$ of participants who reported not to have visited a sex-on-premises venue reported recent poppers use compared to $48.6 \%$ of participants who reported visiting a sex-on-premises venue in the last three months and recent poppers use.

- Level 2: Use of any illicit substance in the last three months

Generally, participants who reported consuming illicit substances in the last three months were more likely to report poppers use in the last three months regardless of having visited a sex-onpremises venue during the last year. The proportion of participants who consumed poppers in the last three months and reported to have visited a sex-on-premises venue in the last year was higher if they consumed illicit substances in the last three months (61.5\%), compared to those who have not consumed illicit substances in the last three months (33.3\%). However, the proportion of participants who consumed poppers in the last three months and did not visit a sex-on-premises venue in the last year was higher if they consumed other illicit drugs in the last three months (21.9\%), compared to those who had not consumed illicit drugs in the last three months $(6.3 \%)$.

- Level 3: Recent tobacco use and visiting an LGBT bar, pub or café

Participants who reported not visiting a sex-on-premises venue, but consumed illicit substances in the last three months, were more likely to use poppers if they also consumed tobacco products in the last three months. The proportion of participants who consumed poppers was $10 \%$ for those not reporting recent tobacco use, compared to $27.4 \%$ of participants who reported both 
recent poppers and tobacco consumption. Likewise, poppers use in the last three months for participants who did not visit a sex-on-premises venue or consumed illicit substances in the last three months predicted visiting an LGBT pub/bar/café in the last 12 months. Participants who reported LGBT pub/bar/café in the last 12 months have a larger likelihood of consuming poppers. 


\section{Discussion}

This study aimed to examine the patterns of poppers use and dependency symptoms in a sample of gay and bisexual young men in Australia, including correlates of recent poppers use with LGBT community-specific concepts, mental and psycho-social health and wellbeing, personal characteristics as well as other licit and illicit substance use. Participants in this sample have reported high levels of lifetime and recent poppers use. This is consistent with the current body of evidence demonstrating higher levels of poppers use in sexual minority men; however, most literature reports even higher levels of poppers use in this population (8-11).

Despite high levels of poppers use in the sample, the prevalence of dependency symptoms and risky consumption were low with WHO ASSIST scores for poppers demonstrating an overall low-risk use of these substances (52). Few participants experienced problems typically indicative of dependency syndromes, including health, social, legal, and financial problems. No correlation between recent poppers use and most other concepts could be identified including mental health, minority stress or psychological distress. This is largely inconsistent with previous research regularly identifying relationships between other substances and these concepts in sexual minority populations (53-55). It is also inconsistent with a recent study from Australia, reporting that sexual minority men who use poppers regularly were less likely to show symptoms of depression (20). Recent poppers use was furthermore not related to personal characteristics including ethnic background, age, sexual minority sub-identity, religion or the extent of others being aware of the participant's sexual identity. These results indicate that poppers use is not related to socio-economic status or psychosocial and mental health and wellbeing. Poppers use is therefore unlikely to represent a coping mechanism in this population.

However, correlations between recent poppers use and three concepts were identified: visiting sex-onpremises venues, visiting licenced venues in the LGBT community, as well as the use of other substances. The relationship between recent poppers use and visiting sex-on-premises-venues is not surprising considering that poppers are regularly used during sexual activity (6). A relationship between the use of poppers and visiting licenced venues in the LGBT community is also consistent with previous research showing that sexual minority people who visit bars and clubs are more likely to engage in substance use due to the higher availability of substances in such environments $(56,57)$. Finally, those who are using poppers were likely to use other substances and to engage in multiple substance use. This finding might provide a route for health promotion interventions to identify sexual minority men using multiple illicit substances via their usage of poppers.

This research further demonstrates that while poppers are widely used among gay and bisexual young men in Australia, its use may have limited consequences and symptoms of dependency are not prevalent. This analysis overall supports the hypothesis that poppers are substances with a considerably lower risk profile than most other licit and illicit substances. An outright ban of this substance as 
currently considered by the Australian Therapeutic Goods Administration (2) and other jurisdictions may be perceived as a disproportionate response considering the low risk profile of these substances. Such a potential criminalisation of a substance used by a large proportion of sexual minority men may lead to further marginalisation of an already stigmatised community (58). There is a need for rigorous regulations of substances containing alkyl nitrites to limit the unwanted effects of poppers without further stigmatising sexual minority men.

\section{Strengths and Limitations}

This study is the first to determine the relationship between poppers use and a variety of concepts in a sample of gay and bisexual young men. This analysis was enabled by the use of valid and reliable measurements of substance use, mental wellbeing, psychological distress, social health, and connectedness to and participation in the LGBT community. A further strength of this study was the use of the WHO ASSIST which allows a more in-depth analysis of poppers use including frequency, psychosocial consequences, and misuse and dependency symptoms. Concerning the methods of this study, the use of hierarchical segmentation analysis provides a multi-causal and multi-level understanding of recent poppers use. In addition, the non-parametric nature of hierarchical segmentation analysis overcomes limitations of the data set such as a lack of normality and linearity.

This study has limitations. Participants were self-selected and may not be representative of gay and bisexual young men in Australia. However, the majority of the sample lived in major cities and were born in Australia, consistent with general population data for this age group (59). Information on state or territory of residence was not available. A limitation of the decision tree technique used is the potential for instability, as small changes in the sample may result in large changes in the tree and the results. Although we used well-established protocols to ensure a stable decision tree (e.g. crossvalidation), future research should replicate these findings to determine the robustness of these findings.

\section{Acknowledgements}

The authors would like to thank Prof Leanne Hides, Prof David J Kavanagh, and Prof Katherine M White for their assistance in designing the study. 


\section{References}

1. Pahlitzsch M, Mai C, Joussen AM, Bergholz R, editors. Poppers maculopathy: complete restitution of macular changes in OCT after drug abstinence. Seminars in ophthalmology; 2016: Taylor \& Francis.

2. Therapeutic Goods Administration. Publication of interim decisions proposing to amend, or not amend, the current Poisons Standard, September 2018. In: Australian Government DoH, Therapeutic Goods Administration, editor. Canberra2018.

3. Independent Scientific Commitee on Drugs. Alkyl Nitrites (Poppers) 2018 [Available from: http://www.drugscience.org.uk/drugs/dissociatives/alkyl-nitrates.

4. Haverkos HW, Kopstein AN, Wilson H, Drotman P. Nitrite inhalants: history, epidemiology, and possible links to AIDS. Environmental Health Perspectives. 1994;102(10):858-61.

5. Hambrick HR, Park SH, Schneider JA, Mayer KH, Carrico AW, Sherman SE, et al. Poppers and PrEP: Use of Pre-exposure Prophylaxis Among Men Who Have Sex with Men Who Use Inhaled Nitrites. AIDS and Behavior. 2018:1-15.

6. Hall TM, Shoptaw S, Reback CJ. Sometimes poppers are not poppers: Huffing as an emergent health concern among MSM substance users. Journal of gay \& lesbian mental health. 2015;19(1):11821.

7. Sanders B. Drugs, clubs and young people: Sociological and public health perspectives: Routledge; 2016.

8. Demant D, Hides L, Kavanagh DJ, White KM, Winstock AR, Ferris J. Differences in substance use between sexual orientations in a multi-country sample: Findings from the Global Drug Survey 2015. Journal of Public Health. 2017;39(3):532-41.

9. Lea T, Prestage G, Mao L, Zablotska I, de Wit J, Holt M. Trends in drug use among gay and bisexual men in Sydney, Melbourne and Queensland, Australia. Drug Alcohol Rev. 2013;32(1):39-46.

10. Holt M, Lea T, Asselin J, Hellard M, Prestage G, Wilson D, et al. The prevalence and correlates of undiagnosed HIV among Australian gay and bisexual men: results of a national, community-based, bio-behavioural survey. Journal of the International AIDS Society. 2015;18(1):20526-.

11. Jin F, Hammoud MA, Maher L, Degenhardt L, Bourne A, Lea T, et al. Age-related prevalence and twelve-month incidence of illicit drug use in a cohort of Australian gay and bisexual men: Results from the Flux Study. Drug and alcohol dependence. 2018;188:175-9.

12. Schmidt AJ, Bourne A, Weatherburn P, Reid D, Marcus U, Hickson F, et al. Illicit drug use among gay and bisexual men in 44 cities: findings from the European MSM Internet Survey (EMIS). International Journal of Drug Policy. 2016;38:4-12.

13. Jeon SY, Kim YJ, Kim Y-H, Shin J, Yun J, Han K, et al. Abuse potential and dopaminergic effect of alkyl nitrites. Neuroscience letters. 2016;629:68-72.

14. Mitchell KR, Prah P, Mercer CH, Datta J, Tanton C, Macdowall W, et al. Medicated sex in Britain: evidence from the third National Survey of Sexual Attitudes and Lifestyles. Sex Transm Infect. 2016;92(1):32-8.

15. Peugh J, Belenko S. Alcohol, drugs and sexual function: a review. Journal of psychoactive drugs. 2001;33(3):223-32.

16. The Merck Manual of Diagnosis and Therapy. 20 ed: The Merck Publishing Group; 2018. Volatile Nitrites.

17. Romanelli F, Smith KM. Recreational Use of Sildenafil by HIV-Positive and -Negative Homosexual/Bisexual Males. Annals of Pharmacotherapy. 2004;38(6):1024-30.

18. Buchbinder SP, Vittinghoff E, Heagerty PJ, Celum CL, Seage III GR, Judson FN, et al. Sexual risk, nitrite inhalant use, and lack of circumcision associated with HIV seroconversion in men who have sex with men in the United States. JAIDS Journal of Acquired Immune Deficiency Syndromes. 2005;39(1):82-9.

19. Zhang $H$, Teng $T$, Lu H, Zhao $Y$, Liu $H$, Yin $L$, et al. Poppers use and risky sexual behaviors among men who have sex with men in Beijing, China. Drug and alcohol dependence. 2016;160:42-8.

20. Prestage G, Hammoud M, Jin F, Degenhardt L, Bourne A, Maher L. Mental health, drug use and sexual risk behavior among gay and bisexual men. International Journal of Drug Policy. 2018;55:16979.

21. French R, Power R. A qualitative study of the social contextual use of alkyl nitrites (poppers) among targeted groups. Journal of Drug Issues. 1998;28(1):57-76. 
22. Race K, Lea T, Murphy D, Pienaar K. The future of drugs: recreational drug use and sexual health among gay and other men who have sex with men. Sexual health. 2017;14(1):42-50.

23. Badge J. Amyl nitrite: Australia's ban on poppers is an attack on gay and bisexual men. The Guardian Australia. 2018 18.10.2018.

24. Spencer S. 'It's a war on bottoms': poppers may soon be banned in Australia pending a TGA decision. StarObserver. 2018 21.08.2018.

25. Duffy N. Government launches review of poppers law after outcry over ban. PinkNews. 2016 26.01.2016.

26. Directive 2005/90/EC (European Union), (2006).

27. Anti-Drug Abuse Act of 1988 (United States of America), (1988).

28. Demant D, Hides L, White KM, Kavanagh DJ. LGBT communities and substance use in Queensland, Australia: Perceptions of young people and community stakeholders. PloS one. 2018;13(9):e0204730.

29. Lelutiu-Weinberger C, Pachankis JE, Golub SA, Ja'Nina JW, Bamonte AJ, Parsons JT. Age cohort differences in the effects of gay-related stigma, anxiety and identification with the gay community on sexual risk and substance use. AIDS and Behavior. 2013;17(1):340-9.

30. Green KE, Feinstein BA. Substance use in lesbian, gay, and bisexual populations: an update on empirical research and implications for treatment. Psychology of Addictive Behaviors. 2012;26(2):265.

31. Humeniuk R, Ali R. Validation of the Alcohol, Smoking and Substance Involvement Screening Test (ASSIST) and pilot brief intervention: a technical report of phase II findings of the WHO ASSIST Project. Validation of the Alcohol, Smoking and Substance Involvement Screening Test (ASSIST) and pilot brief intervention: a technical report of phase II findings of the WHO ASSIST Project2006.

32. Frost DM, Meyer IH. Measuring community connectedness among diverse sexual minority populations. Journal of sex research. 2012;49(1):36-49.

33. Mills TC, Stall R, Pollack L, Paul JP, Binson D, Canchola J, et al. Health-related characteristics of men who have sex with men: a comparison of those living in" gay ghettos" with those living elsewhere. American journal of public health. 2001;91(6):980.

34. Ross MW, Tikkanen R, Berg RC. Gay community involvement: its interrelationships and associations with Internet use and HIV risk behaviors in Swedish men who have sex with men. Journal of homosexuality. 2014;61(2):323-33.

35. Sklar SM, Annis HM, Turner NE. Development and validation of the drug-taking confidence questionnaire: A measure of coping self-efficacy. Addictive Behaviors. 1997;22(5):655-70.

36. Glavak Tkalić R, Sučić I, Dević I. Motivation for substance use: Why do people use alcohol, tobacco and marijuana? Društvena istraživanja: časopis za opća društvena pitanja. 2013;22(4):601-25.

37. Keyes CL. Brief description of the mental health continuum short form (MHC-SF). 2009.

38. Kessler RC, Andrews G, Colpe L, Hiripi E, Mroczek DK, Normand S-L, et al. Short screening scales to monitor population prevalences and trends in non-specific psychological distress. Psychological medicine. 2002;32(6):959-76.

39. Smith BW, Dalen J, Wiggins K, Tooley E, Christopher P, Bernard J. The brief resilience scale: assessing the ability to bounce back. International journal of behavioral medicine. 2008;15(3):194-200.

40. Lewis RJ, Derlega VJ, Berndt A, Morris LM, Rose S. An empirical analysis of stressors for gay men and lesbians. Journal of Homosexuality. 2002;42(1):63-88.

41. Endler NS, Parker J. Coping inventory for stressful situations: Multi-Health systems Incorporated; 1990.

42. Bush K, Kivlahan DR, McDonell MB, Fihn SD, Bradley KA. The AUDIT alcohol consumption questions (AUDIT-C): an effective brief screening test for problem drinking. Archives of internal medicine. 1998;158(16):1789-95.

43. Bryne BM. Structural equation modeling with EQS and EQS/Windows. Thousand Oaks, Califomia: Sage Publications. 1994.

44. Medina-Borja A, Pasupathy KS, editors. Uncovering complex relationships in system dynamics modeling: Exploring the use of CART, CHAID and SEM. Syst Dyn Soc Conf; 2007.

45. Sierra RC, Oviedo-Trespalacios O, Candelo JE, Soto JDJES, Research P. Assessment of the risk of failure of high voltage substations due to environmental conditions and pollution on insulators. 2015;22(13):9749-58.

46. Westreich D, Lessler J, Funk MJJJoce. Propensity score estimation: neural networks, support vector machines, decision trees (CART), and meta-classifiers as alternatives to logistic regression. 2010;63(8):826-33. 
47. Kass GVJJotRSSSC. An exploratory technique for investigating large quantities of categorical data. $1980 ; 29(2): 119-27$.

48. Tiet QQ, Ilgen MA, Byrnes HF, Moos RHJAC, Research E. Suicide attempts among substance use disorder patients: an initial step toward a decision tree for suicide management. 2006;30(6):9981005.

49. Oviedo-Trespalacios O, Scott-Parker B. Fast and furious: a neglected issue in health promotion among young drivers. Health promotion journal of Australia. 2019.

50. Holgado D, Maya-Jariego I, Palacio J, Oviedo-Trespalacios Ó. Two profiles of child labor in the Colombian Caribbean coast: Children relocated to suburban areas compared to the key role of social and labor characteristics of mothers in urban settings. Indicators of quality of life in Latin America: Springer; 2016. p. 251-73.

51. Lakerveld J, Loyen A, Schotman N, Peeters CF, Cardon G, van der Ploeg HP, et al. Sitting too much: a hierarchy of socio-demographic correlates. Preventive medicine. 2017;101:77-83.

52. WHO ASSIST Project Research Group. The alcohol, smoking and substance involvement screening test (ASSIST): development, reliability and feasibility. Addiction. 2002;97(9):1183-94.

53. Lea T, de Wit J, Reynolds R. Minority Stress in Lesbian, Gay, and Bisexual Young Adults in Australia: Associations with Psychological Distress, Suicidality, and Substance Use. Arch Sex Behav. 2014;43(8):1571-8.

54. Kecojevic A, Wong CF, Corliss HL, Lankenau SE. Risk factors for high levels of prescription drug misuse and illicit drug use among substance-using young men who have sex with men (YMSM). Drug \& Alcohol Dependence. 2015;150:156-63.

55. Hatzenbuehler ML, Pachankis JE. Stigma and Minority Stress as Social Determinants of Health Among Lesbian, Gay, Bisexual, and Transgender Youth: Research Evidence and Clinical Implications. Pediatric Clinics of North America. 2016;63(6):985-97.

56. Trocki KF, Drabble L, Midanik L. Use of heavier drinking contexts among heterosexuals, homosexuals and bisexuals: results from a National Household Probability Survey. Journal of studies on alcohol. 2005;66(1):105-10.

57. Chow C, Vallance K, Stockwell T, Macdonald S, Martin G, Ivsins A, et al. Sexual identity and drug use harm among high-risk, active substance users. Culture, Health \& Sexuality. 2013;15(3):31126.

58. Demant D, Oviedo-Trespalacios O, Carroll J-A, Ferris JA, Maier L, Barratt MJ, et al. Do people with intersecting identities report more high-risk alcohol use and lifetime substance use? 2018;63(5):621-30.

59. Australian Bureau of Statistics. Regional Population Growth, Australia, 2015-2018. Canberra2017. 
Table 1 Sample Characteristics and general poppers use $(n=836)$

\begin{tabular}{|l|l|}
\hline \multicolumn{2}{|c|}{ Demographics } \\
\hline Age, mean (SD) & 23.4 years (4.8) \\
\hline Sexual orientation, identifies as &.$/$ \\
\hline$-\quad$ Gay & $81.6 \%(n=682)$ \\
\hline$-\quad$ Bisexual & $12.0 \%(n=100)$ \\
\hline$\quad$ Other & $6.5 \%(n=54)$ \\
\hline Identifies as Caucasian or White & $82.3 \%(n=688)$ \\
\hline Living area (major city) & $69.3 \%(n=579)$ \\
\hline Born in Australia & $80.3 \%(n=671)$ \\
\hline \multicolumn{2}{|c|}{ Poppers Use } \\
\hline WHO ASSIST Score Poppers, mean (SD) & $1.2(3.1)$ \\
\hline Lifetime use & $37.7 \%(n=315)$ \\
\hline Past 12 months use & $24.4 \%(n=204)$ \\
\hline Past 3 months use & $16.5 \%(n=138)$ \\
\hline Last month use & $12.3 \%(n=103)$ \\
\hline $\begin{array}{l}\text { Age of onset (first poppers use), mean } \\
\text { (SD) }\end{array}$ & $20.4(3.6)$ \\
\hline
\end{tabular}


Table 2 Poppers use characteristics among those who have used poppers in their lifetime $(n=315)$

\begin{tabular}{|l|l|}
\hline \multicolumn{2}{|c|}{ Poppers Use Variables } \\
\hline WHO ASSIST Score Poppers, mean (SD) & $3.1(4.4)$ \\
\hline Past year use & $64.8 \%(n=204)$ \\
\hline Past 3 months use & $43.8 \%(n=138)$ \\
\hline Last month use & $32.7 \%(n=103)$ \\
\hline At least weekly use in past three months & $13.5 \%(n=42)$ \\
\hline $\begin{array}{l}\text { Strong desire/urge to use poppers at least } \\
\text { once a week (past three months) }\end{array}$ & $8.9 \%(n=27)$ \\
\hline $\begin{array}{l}\text { Poppers use lead to health, social, legal } \\
\text { and financial problems in past three } \\
\text { months }\end{array}$ & $3.0 \%(n=9)$ \\
\hline $\begin{array}{l}\text { Failed what was normally expected due } \\
\text { to poppers use in the past three months }\end{array}$ & $1.3 \%(n=4)$ \\
\hline $\begin{array}{l}\text { Other person was concerned about } \\
\text { poppers use (ever) }\end{array}$ & $5.2 \%(n=16)$ \\
\hline $\begin{array}{l}\text { Tried and failed to control, cut down or } \\
\text { stop using poppers (ever) }\end{array}$ & $6.6 \%(n=20)$ \\
\hline
\end{tabular}


Figure 1: CHAID tree for poppers consumption in the last three months

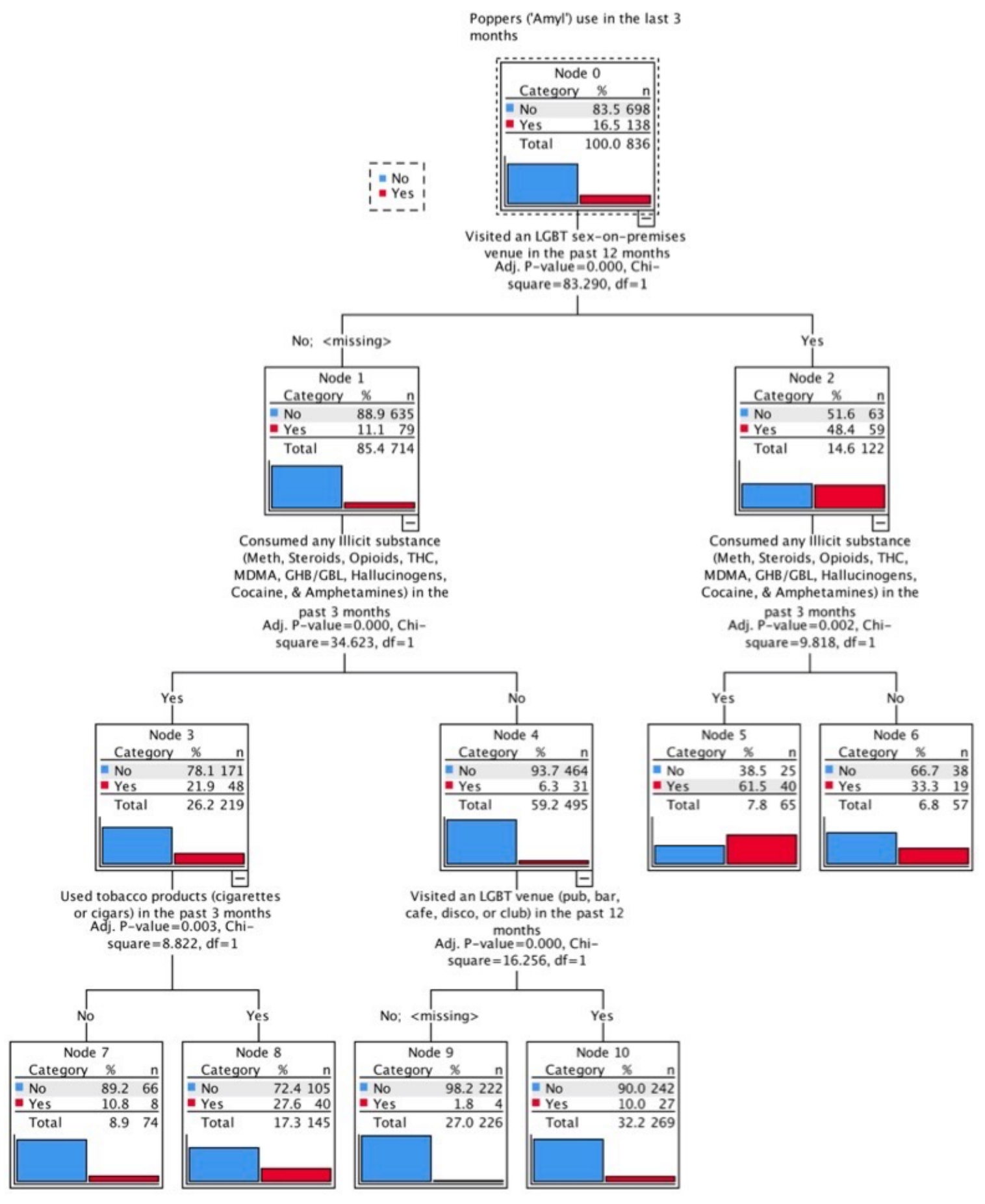

